\title{
Anatomía y desarrollo de estambres y carpelos en Drimys granadensis (Winteraceae)
}

\author{
Xavier Marquínez-Casas \\ Departamento de Biología, Facultad de Ciencias, Universidad Nacional de Colombia. Bogotá, Colombia; \\ xmarquinezc@unal.edu.co
}

Recibido 12-VIII-2013. Corregido 24-I-2014. $\quad$ Aceptado 26-II-2014.

\begin{abstract}
Anatomy and development of stamens and carpels of Drimys granadensis (Winteraceae). Winteraceae has long been considered a family with early diversification among angiosperms, with characters such as: flowers with many spirally arranged parts and apocarpic ovary formed by plicated carpels with sessile stigma. In Drimys, the presence or absence of conspicuous glands on the connective of the stamens have been used as a taxonomic character, and it is considered a synapomorphy for the clade including Drimys angustifolia, D. brasiliensis, D. granadensis and D. roraimensis (Northeastern clade); however, the anatomy of stamens and carpels has only been studied in detail for $D$. winteri (Southwestern clade). In this research, the presence and the structure of glands on the connective of stamens was studied in seven species of the genus from herbarium specimens, and a detailed study of the anatomy and development of stamens and carpels was carried out by scanning electron and optic microscopy in Drimys granadensis. We found similarities between D. granadensis and $D$. winteri for the following characters: Basic type anther wall formation, secretory tapetum that collapses at maturity, intermediate type microsporogenesis with formation of a transient cell plate in telophase I, ascidiated carpel due to the formation of an adaxial lip during development, stigma closed by interdigitation of epidermal cells. We also determined that the large glands on anther mature connective are originated by an overgrowth of subepidermal oil cells; this character is a Northeastern Drimys clade synapomorphy, while it was absent in both Drimys of Southwestern clade (which includes D. andina, D. confertifolia and D. winteri), and the rest of the Winteraceae. We are proposing the hypothesis that the highly variable enviromental conditions in the tropics where Drimys Northeastern clade is distributed, with a wide range of pollinators, would be associated with the emergence of glandular conspicuously stamens; while, as a prediction to be confirmed, temperated Southwestern clade species, without conspicuous glands, should have a smaller range of visitors and/or pollinators, or even be anemophilous species as Drimys confertifolia. Rev. Biol. Trop. 62 (3): 1147-1159. Epub 2014 September 01.
\end{abstract}

Key words: microsporogenesis, ascidiated carpel, idioblastic oil cells, secretory tapetum.

Las Winteraceae han sido consideradas durante mucho tiempo como una familia de diversificación temprana en las angiospermas (Takhtajan, 1980; Cronquist, 1981), por diversas características, entre ellas: presentar flores con numerosas partes dispuestas en varios verticilos o en espiral, ovario frecuentemente apocárpico formado por carpelos con estigma sésil y de tipo generalmente plicado.

Diversos autores han propuesto que los estambres laminares y con tres haces vasculares son plesiomórficos en angiospermas
(Canright, 1952; Eames, 1961; Takhtajan, 1991); a partir de ellos se habría originado el estambre diferenciado en filamento y antera. Siguiendo esta hipótesis, Bailey \& Nast (1943) y Sampson (1987), reconocen que los estambres en Winteraceae presentan un solo haz vascular, pero indican la presencia ocasional de haces laterales vestigiales, lo cual evidenciaría una reducción a partir de un estambre con tres haces. Al interior de las Winteraceae algunos caracteres asociados a la distribución, estructura y desarrollo de estambres y polen resultan 
de importancia taxonómica a nivel de géneros; por ejemplo, la posición de las anteras (apical o subapical) y su orientación (transversal o lateral) (Bailey \& Nast, 1943; Endress \& Hufford, 1989; Endress, Igersheim, Sampson, \& Schatz, 2000). En el género Drimys la presencia o no de glándulas conspicuas en el conectivo del estambre es utilizada como caracter taxonómico (Smith, 1943), en tanto que el conectivo glandular es considerado como una sinapomorfía para el clado conformado por Drimys angustifolia Miers, D. brasiliensis Miers, D. granadensis L.f. y D. roraimensis (A.C.Sm.) Ehrend. \& Gottsb. (Clado nororiental sensu Marquínez, Lohmann, Faria-Salatino, Salatino, \& González, 2009b; Marquínez, 2009).

En algunas Winteraceae la microsporogénesis es de tipo simultáneo: Drimys (Schnarf, 1931), Pseudowintera (Bhandari, 1963; Bhandari, 1971); sin embargo, en otras se presenta un tipo intermedio entre simultáneo y sucesivo, caracterizado por la aparición de una placa celular transitoria después de la primera división meiótica: Tasmannia (Prakash, Lim, \& Sampson, 1992), Zygogynum (Swamy, 1952), Belliolum (Cairney, 1984), Exospermum (Smissen, 1993), Drimys winteri J.R. Forst. \& G. Forst. (Bhandari \& Venkataram, 1968), Pseudowintera, (Sampson, 1963; Sampson, 1970; Furness, Rudall, \& Sampson, 2002).

El desarrollo de la antera ha sido explorado en especies de los géneros Tasmannia (Prakash et al., 1992), Takhtajania (Tobe \& Sampson, 2000) y Zygogynum (Swamy, 1952). En el género Drimys, el desarrollo de la pared de los estambres ha sido estudiada únicamente en la especie D. winteri (Bandhari \& Venkataraman, 1968).

El polen maduro en Winteraceae puede estar conformando por mónadas o tétradas (van der Ham \& van Heuven, 2002; Sampson, 2007), puede presentar o no papilas y/o annulus, su exina puede ser reticulada o microreticulada y su mitosis puede ser sincrónica o asincrónica en cada uno de los granos de polen que conforman la tétrada (Bailey \& Nast, 1943; Fiser \& Walker, 1967; Praglowski, 1979; Sampson, 1974; Sampson, 1981; Sampson, 2000a; Sampson, 2000b; van der Ham \& van Heuven, 2002).

En cuanto a los carpelos, existen dos formas de desarrollo: ascidiada o plicada. La condición plicada es considerada como ancestral en angiospermas en trabajos clásicos, dando lugar a diferentes tendencias de especialización (Bailey \& Swamy, 1951). Sin embargo, los análisis moleculares recientes y la revisión de evolución de caracteres en contextos filogenéticos aportan evidencia de que la condición ascidiada es plesiomórfica (Doyle \& Endress, 2000; Soltis, Soltis, Endress, \& Chase, 2005; Endress \& Doyle, 2009). La teoría del origen plicado de los carpelos se basó en el estudio de este carácter en Winteraceae, que además es la única familia en Eumagnoliales que presenta las dos formas de carpelos, ascidiado y plicado (Igersheim \& Endress, 1997; Soltis et al., 2005).

La noción de carpelos abiertos en el momento de la antesis para las Winteraceae y Degeneriaceae fue sugerida por Bailey \& Swamy (1951). No obstante, Igersheim \& Endress (1997), Endress \& Igersheim (2000) y Endress \& Doyle (2009) demostraron que los carpelos de Winteraceae (y de su grupo hermano, las Canellaceae) se encuentran completamente cerrados de manera posgénita por fusión temprana de las epidermis inmaduras. Sin embargo, otras características permiten diferenciar estas dos familias hermanas: (1) el ovario paracárpico en Canellaceae y apocárpico o eusincárpico en Winteraceae (una condición paracárpica atípica ocurre en Takhtajania perrieri; Endress et al., 2000); (2) el cierre del carpelo por secreción en Canellaceae pero no en Winteraceae (Igersheim \& Endress, 1997); (3) presencia de estilo y de estigma lobado en Canellaceae y sésil en Winteraceae con una cresta corta o una doble cresta larga (Igersheim \& Endress, 1997); (4) en Canellaceae estigma papilado unicelular y fuertemente secretor; y unicelular-papilado o multicelular-multiseriado-papilado y débil o fuertemente secretor en Winteraceae (Igersheim \& Endress, 1997).

Los óvulos de Winteraceae y Canellaceae también difieren en la presencia de un 
micrópilo formado por los dos integumentos en Canellaceae versus un micrópilo formado únicamente por el integumento interno en Winteraceae (con pocas excepciones; Igersheim \& Endress, 1997); y en la forma anular del integumento interno en Canellaceae versus semianular en Winteraceae (Imaichi, Kato, \& Okada, 1995; Igersheim \& Endress, 1997; Endress, 2011).

Marquínez et al. (2009b), basado en análisis de secuencias nucleares (ITS) y de cloroplasto ( $r p \mathrm{~S} 16$ y $p s b \mathrm{~A}-t r n \mathrm{H}$ ), propusieron la existencia de dos clados en Drimys; uno de distribución suroccidental $\left(>30^{\circ}\right.$ de latitud sur) conformado por $D$. confertifolia Phil., $D$. Winteri y D. Andina (Reiche) Rodr. \& Quez. $\mathrm{y}$ el otro nororiental (entre $30^{\circ}$ latitud sur y $23^{\circ}$ latitud norte) constituido por D. angustifolia, D. brasiliensis, D. granadensis y $D$. roraimensis. Dado que los estudios previos de anatomía y desarrollo de estambres y carpelos se han centrado en la especie D. winteri (Chile y Argentina), correspondiente al clado suroccidental, este trabajo pretende estudiar estos mismos aspectos en $D$. granadensis, especie de amplia distribución (Bosques montanos centroamericanos y bosques andinos de Colombia, Ecuador y Perú) en el clado nororiental, para poder establecer similitudes y diferencias.

\section{MATERIALES Y MÉTODOS}

Para determinar la presencia o ausencia y tipo de glándulas en el conectivo del estambre, se revisaron 809 ejemplares, provenientes de 20 herbarios, de las siete especies (ocho taxones) pertenecientes al género Drimys (entre paréntesis, ejemplar representativo-herbario): D. andina (Reiche) Rodr. \& Quez. (L. Jungner 622-GB, Schajovski 163-M; 992); D. angustifolia Miers (Wasum 4791-MA,NY,US; Wasum 4809-NY), Drimys brasiliensis (St. Hil.) Miers (Anderson 8146-NY,MEXU; Collares 46-NY); D. confertifolia Phil. (Aravena 30-UC; Solbrig 3816-NY,UC,US); D. granadensis L. f. (Acevedo 1382-HUA; Marquínez 001-004 COL); D. roraimensis (A. C. Smith) Ehrend. \& Gottsb. (Pruski \& Huber 3634-NY,VEN; Holst
3689-MO,NY); D. winteri var. winteri J. Forst. \& G. Forst. (Poelt S.N.-M; Rae \& Goodall 646-UC) D. winteri var chilensis (DC) A. Gray (SN 45307-UCA\# 1357032; Ornuff 9116-UC); (Cf. Marquínez, 2009). Algunas flores fueron hidratadas en agua con detergente por cinco minutos en ebullición, y luego observadas y fotografiadas bajo microscopio estereoscopio.

Adicionalmente, se recolectaron botones florales y flores de $D$. granadensis en diferentes estados de desarrollo pertenecientes a una población situada en Altos de Yerbabuena, cerros orientales de la Sabana de Bogotá (452'40" N - 7400'04" W; 2808 msnm; Cundinamarca, Colombia; ejemplares testigo: Marquinez 001-004, COL $=$ Herbario Nacional Colombiano).

Para microscopía óptica de alta resolución (secciones semifinas 1-2 $\mu \mathrm{m}$ ), se siguieron los procedimientos indicados por Romero (2003): las muestras fueron disectadas en campo y fijadas en glutaraldehido $2.5 \%$ (preparado en solución amortiguadora de Millogin $0.2 \mathrm{M}, \mathrm{pH}$ 7.4) por 48 horas; luego se lavaron en solución amortiguadora por 15 minutos y postfijaron en tetróxido de osmio $1 \%$ durante una hora bajo rotación continua a $4^{\circ} \mathrm{C}$. Se lavaron con solución amortiguadora (15 minutos), se deshidrataron en series de EtOH 70\%, 90\%, 95\%, $100 \%$; por $5,10,20$ y 60 minutos, respectivamente; y óxido de propileno 15 minutos; se preimbibieron en una mezcla de Epon-Araldita (Kit PolyScience) y óxido de propileno 1:1 (1 hora), y posteriormente en resina ( 2 horas). Se polimerizaron en resina por 48 horas a $60^{\circ} \mathrm{C}$ seguidas de un enfriamiento lento por 24 horas más. De los bloques se obtuvieron secciones semifinas $(1-2 \mu \mathrm{m})$ en un ultramicrótomo LBK4802-A con cuchilla de vidrio, las cuales fueron coloreadas con azul de toluidina $(0.05 \%)$ y fijadas con citoresina para observación bajo microscopio óptico.

Otras muestras de botones y flores fueron recolectadas y fijadas en FAA (10:5:85, formol: acido acético glacial: EtOH 70\%) por 24 horas y luego fueron tratadas con los protocolos modificados de Johansen (1940) para microscopía óptica convencional, así: Deshidratación 

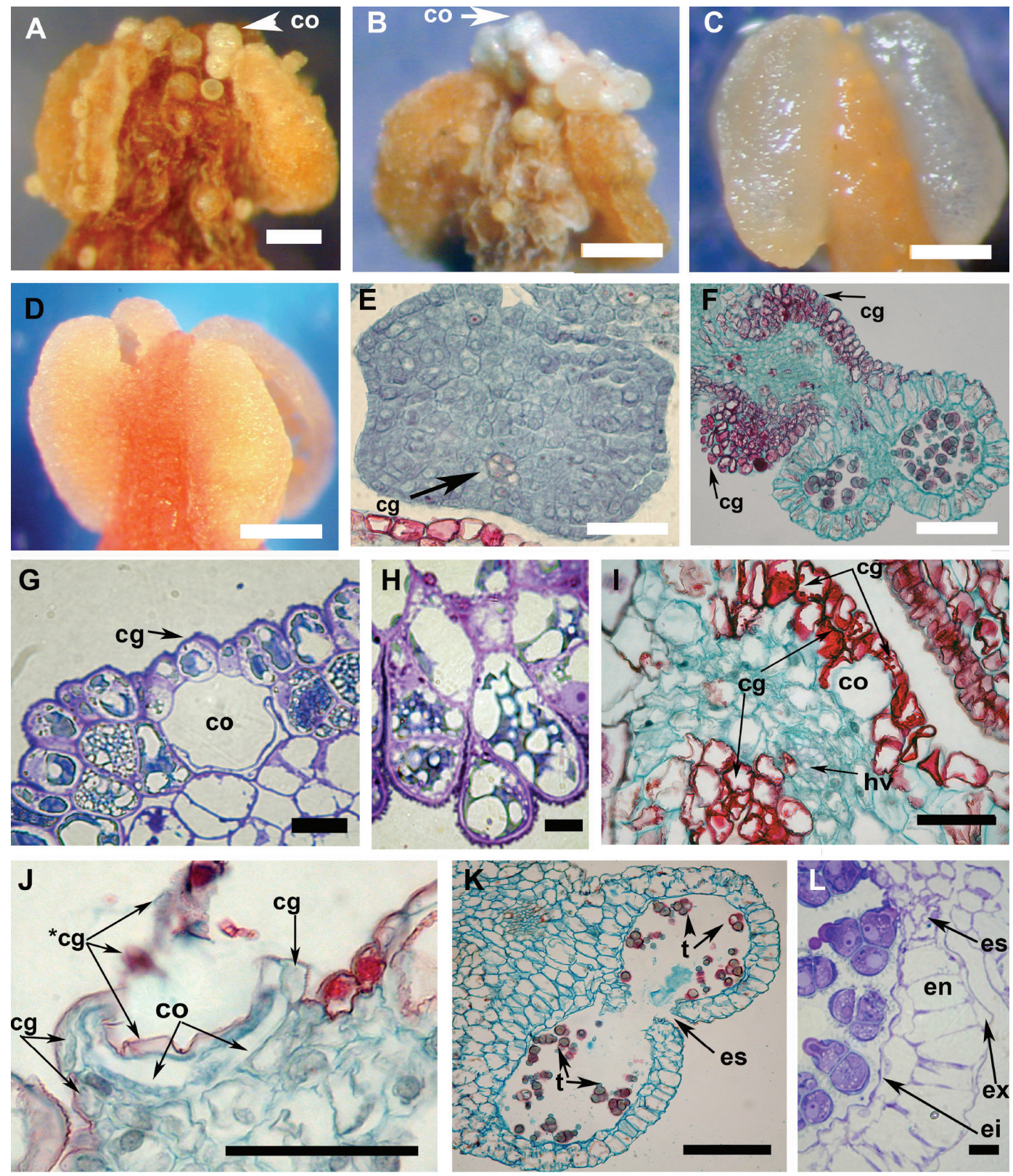

Fig. 1. A-D. Estambres de especies de Drimys: A. D. roraimensis (Pruski \& Huber 3634); B. D. granadensis (Acevedo 1382); C. D. confertifolia (Solbrig 3816); D. D. winteri chilensis (s.c. 45307, UCA 1357032). E-L. Sección transversal de estambres de Drimys granadensis (Marquínez $003 \mathrm{COL}$ ), E. antera joven con inicio de diferenciación de células glandulares, F. Antera madura en preantesis con células glandulares del conectivo; G. Detalle de la epidermis y subepidermis glandular del filamento; H. Detalle de las células glandulares de la cara adaxial del conectivo; I-J. Detalle de las células glandulares y oleíferas de la cara abaxial del conectivo; K. Antera dehiscente; L. Engrosamientos de la pared de las células del endotecio en antera madura; $\mathbf{c g}=$ células glandulares, ${ }^{*} \mathbf{c g}=$ restos de células glandulares, $\mathbf{c o}=$ células oleíferas idioblásticas. $\mathbf{e i}=$ estratos intermedios, $\mathbf{e n}=$ endotecio, $\mathbf{e s}=$ estomio, $\mathbf{e x}=$ exotecio, $\mathbf{h v}=$ haz vascular. $\mathbf{A}-\mathbf{D}=$ Estereomicroscopio, E,F,I,J,K.

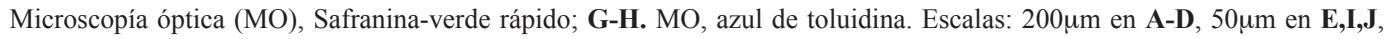
$100 \mu \mathrm{m}$ en $\mathbf{F}, \mathbf{K}$ y $10 \mu \mathrm{m}$ en $\mathbf{G , H}, \mathbf{L}$. 
en series de EtOH (70 al 100\%) y de EtOH 100\%-histoclear (90:10, 70:30, 50:50, 30:70, 10:90, 100) cada una por 12 horas; imbibición en parafina $\left(60^{\circ} \mathrm{C}\right), 3$ cambios por 24 horas $\mathrm{c} / \mathrm{u}$; secciones seriadas o individuales en micrótomo de rotación y fijación en láminas con ayuda de adhesivo de Haupt; desparafinado mediante pasos de Xilol, Xilol:EtOH 100\%, EtOH 100\%, 95\%, 70\%, 50\%; tinción en safranina por 18 horas, lavado en agua destilada y deshidratación en EtOH 50\%, 70\% y 95\%; contratinción con fast-green por 12 minutos, deshidratación en EtOH 100\%, EtOH 70:Xilol 30, EtOH 50:xilol 50, xilol 100\%, colocación de una gota de citoresina y cubreobjetos. Para la observación de los estados de la microsporogénesis, las flores fijadas en FAA y luego en $\mathrm{EtOH} 70 \%$ fueron disectadas y las anteras removidas y disectadas sobre el portaobjetos en unas pocas gotas del reactivo de clareamiento de Herr modificado (acido láctico, hidrato de cloral, fenol, aceite de clavo, histoclear en proporciones 2:2:2:2:1 por peso; González \& Rudall, 2003).

Todos los micropreparados fueron observados con un microscopio Nikon Eclipse E-200; para las observaciones bajo estereoscopio se empleó un equipo Nikon SMZ 800; en ambos se tomaron las fotos con una cámara Nikon 950 Coolpix incorporada a los equipos ópticos. Para microscopía electrónica de barrido, las muestras fijadas en FAA y EtOH $70 \%$ fueron disectadas, secadas por su punto crítico en un equipo Bal-tec CPB030, metalizadas con oro-paladio en un metalizador Fisons-Polaron, modelo SC-500 y examinadas y fotografiadas en un microscopio electrónico de barrido Quanta 200 FEI del Laboratorio de
Microscopía Electrónica, Centro de Equipos Interfacultades de la Universidad Nacional de Colombia (CEIF).

\section{RESULTADOS}

\section{Morfoanatomía de estambres y desa-} rrollo de células secretoras y oleíferas: En el género Drimys los estambres son libres y las anteras son tetrasporangiadas; las tecas están en posición subapical y orientadas lateralmente respecto al conectivo. En Drimys angustifolia, D. brasiliensis, D. granadensis y D. roraimensis, se observan externamente grandes células oleíferas idioblásticas en posición apical sobre el conectivo (Fig. 1A, Fig. 1B); en tanto que en $D$. andina, $D$. confertifolia, y $D$. winteri no se presentan estas células oleíferas, o si se presentan, son pequeñas e inconspicuas (Fig. 1C, Fig. 1D).

En D. granadensis el inicio de diferenciación de células secretoras en el conectivo ocurre en anteras muy jóvenes (Fig. 1E); en estambres de flores en preantesis se observan una a dos capas de células secretoras en la cara adaxial (Fig. 1F, Fig. 1I) y tres a cinco capas en la cara abaxial del conectivo (Fig. 1F, Fig. $1 \mathrm{H}$ ); en las flores maduras, las células oleíferas aumentan su tamaño y se hacen prominentes sobre la superficie (Fig. 1J).

El filamento presenta también externamente dos capas de células secretoras (Fig. 1G; epidérmica y subepidérmica); presentándose grandes células oleíferas idioblásticas subepidérmicas; hacia el interior del estambre el único haz vascular permanece simple, u ocasionalmente se bifurca hacia las dos tecas.

Fig. 1. A-D. Stamens of Drimys species; A. D. roraimensis (Pruski \& Huber 3634), B. D. granadensis (Acevedo 1382); C. D. confertifolia (Solbrig 3816); D. D. winteri chilensis (s.c. 45307, UCA 1357032). E-L. Cross sections of D. granadensis stamens (Marquinez $003 \mathrm{COL}$ ), E. Young anther begining glandular cell differentiation, F. Preanthesis mature anther with connective glandular cells; G. Detail of the glandular epidermis and subepidermis of the filament; H. Detail of the adaxial side glandular cells of the connective; I-J. Detail of oil and glandular cells on the abaxial surface of the connective; K. Dehiscent anther; L. Wall thickenings of endothecium cells in mature anther. $\mathbf{c g}=$ glandular cells, $* \mathbf{c g}=$ glandular cell debris, $\mathbf{c o}=$ idioblastic oil cells, $\mathbf{e i}=$ intermediate strata, $\mathbf{e n}=$ endothecium, $\mathbf{e s}=$ estomio, $\mathbf{e x}=$ exotecio, $\mathbf{h v}=$ vascular bundle. A-D = Stereomicrocopy; E,F,I,J,K. Optical microscopy (OM), Safranin-fast green; G-H. MO, toluidine blue. Scales: $200 \mu \mathrm{m}$ in A-D, $50 \mu \mathrm{m}$ in $\mathbf{E ,} \mathbf{I}, \mathbf{J}, 100 \mu \mathrm{m}$ in $\mathbf{F , K}$ and $10 \mu \mathrm{m}$ in $\mathbf{G}, \mathbf{H}, \mathbf{L}$. 
La antera está conformada por un conectivo y dos tecas (Fig. 1F, Fig. 1K), cada una con dos sacos polínicos. Las paredes de los sacos polínicos presentan exotecio, estratos intermedios y tapetum secretor que colapsa en la madurez (Fig. 1F, Fig. 1K), así como un endotecio bien desarrollado con engrosamientos en forma de 'U' (Fig. 1K, Fig. 1L); estos engrosamientos pueden también estar esporádicamente presentes en células del exotecio; la dehiscencia de cada teca ocurre por un único estomio longitudinal (Fig. 1K).

Desarrollo de la pared de la antera y microesporogénesis en $D$. granadensis: la formación de la pared de la antera es de tipo básico (sensu Dahlgren, 1991), puesto que la capa hipodérmica arquesporial se divide dando lugar a la capa parietal primaria y a una capa esporógena, y la capa parietal primaria se divide sucesivamente dando lugar primero a dos (Fig. 2A, Fig. 2B) y luego a cuatro capas celulares (Fig. 2C) las cuales al madurar dan lugar al endotecio, a las dos capas o estratos intermedios y al tapetum secretor con células multinucleadas (Fig. 2D), que colapsa en la madurez (Fig. 2E).

Las células madres de los granos de polen presentan núcleo prominente y citoplasma denso y están rodeadas por una pared lisa, de grosor variable, conformada principalmente por calosa (Fig. 2F); entran en primera división meiótica (Fig. 2G), y durante la telofase conforman una placa celular evanescente (transitoria), que luego desaparece (Fig. 2H). Posteriormente, ocurre la segunda división reduccional (Fig. 2I, Fig. 2J), que culmina con la conformación de las paredes celulares que dan lugar a cuatro células por invaginación centrípeta (Fig. 2K). Las microsporas permanecen en tétradas permanentes, la exina e intina maduran (Fig. 2L) y cada una de las microsporas se divide para dar lugar a un núcleo vegetativo, grande y difuso, y un núcleo generativo pequeño y denso (Fig. 2L, Fig. M). En el momento de la antesis los granos de polen son binucleados, presentan una papila por protrusión de la intina y conforman tétradas usualmente tetrahédricas (Fig. 2M), aunque a veces se presentan tétradas decusadas (Fig. 2L). Las tétradas son acalamitadas puesto que cada grano de polen posee su propia ectexina, aún cuando esta pueda estar poco desarrollada en la parte septal; la exina de cada grano es independiente en el centro de la tétrada (Fig. 2M). El polen es semitectado y columelado, con las ornamentaciones de tipo reticulado. Entre las columelas es posible observar la presencia de cemento polínico.

Fig. 2. A-D. Etapas sucesivas de formación de la pared de la antera en Drimys granadensis, las flechas señalan células originadas por división periclinal; A-B. primera división de la capa subepidérmica; C. Segunda división, se numeran las capas que van a dar respectivamente a: (1) endotecio, $(2,3)$ estratos intermedios y (4) tapetum; D-E. Desarrollo del tapetum: D. Las células madres de los granos de polen conforman un tejido continuo en tanto que culminan meiosis, el tapetum es de tipo secretor y presenta células bi- a tetranucleadas; E. Tapetum colapsado; F-M. etapas sucesivas de la microsporogénesis; figF. céĺula madre del grano de polen; G. metafase I; H. telofase I, las flechas indican la posición de la placa celular transitoria, I. metafase II; J. telofase II; K. tétradas con paredes celulares en formación; L-M. Polen maduro, tetradas persistentes en estado binucleadopunta de flecha negra = núcleo generativo, punta de flecha blanca = núcleo vegetativo. ta = tapetum, $\mathbf{t}=$ tétradas. Microscopía óptica $(\mathrm{MO})$, safranina-verde rápido, A-E, $\mathbf{I} ; \mathbf{M O}$, azul de toluidina $=\mathbf{M} ; \mathrm{MO}$, aclaradas con reactivo de Herr F-H, J-L. Escalas $=10 \mu \mathrm{m}$.

Fig. 2. A-D. Successive stages of anther wall formation in D. granadensis, the arrows indicate cells originated by periclinal division; A-B. first division of the subepidermal layer; C. Second division, layers numbered will originated respectively: (1) endothecium (2,3) intermediate layers, and (4) tapetum; D-E. Tapetum development; D. Mother cells of pollen grains form a continuous tissue while culminate meiosis, the tapetum is secretory type and presents a bi-tetranucleate cells, E. Collapsed tapetum; F-M. Successive stages of microsporogenesis; F. mother cell of pollen grain; G. metaphase I; H. telophase I, arrows indicate the position of the transient cell plate; I. metaphase II; J. telophase II; K. tetrads with cell walls in formation; L-M. Mature pollen, persistent tetrads in binucleate stage, black arrowhead $=$ generative nucleus, white arrowhead $=$ vegetative nucleus. $\mathrm{ta}=$ tapetum, $\mathrm{t}=$ tetrads. Optical microscopy $(\mathrm{OM})$, safranin-fast green, $\mathbf{A}-\mathbf{E}, \mathbf{I}, \mathrm{MO}$, toluidine blue = M, MO, cleared with Herr reagent FH, JL. Scales $=10 \mu \mathrm{m}$. 

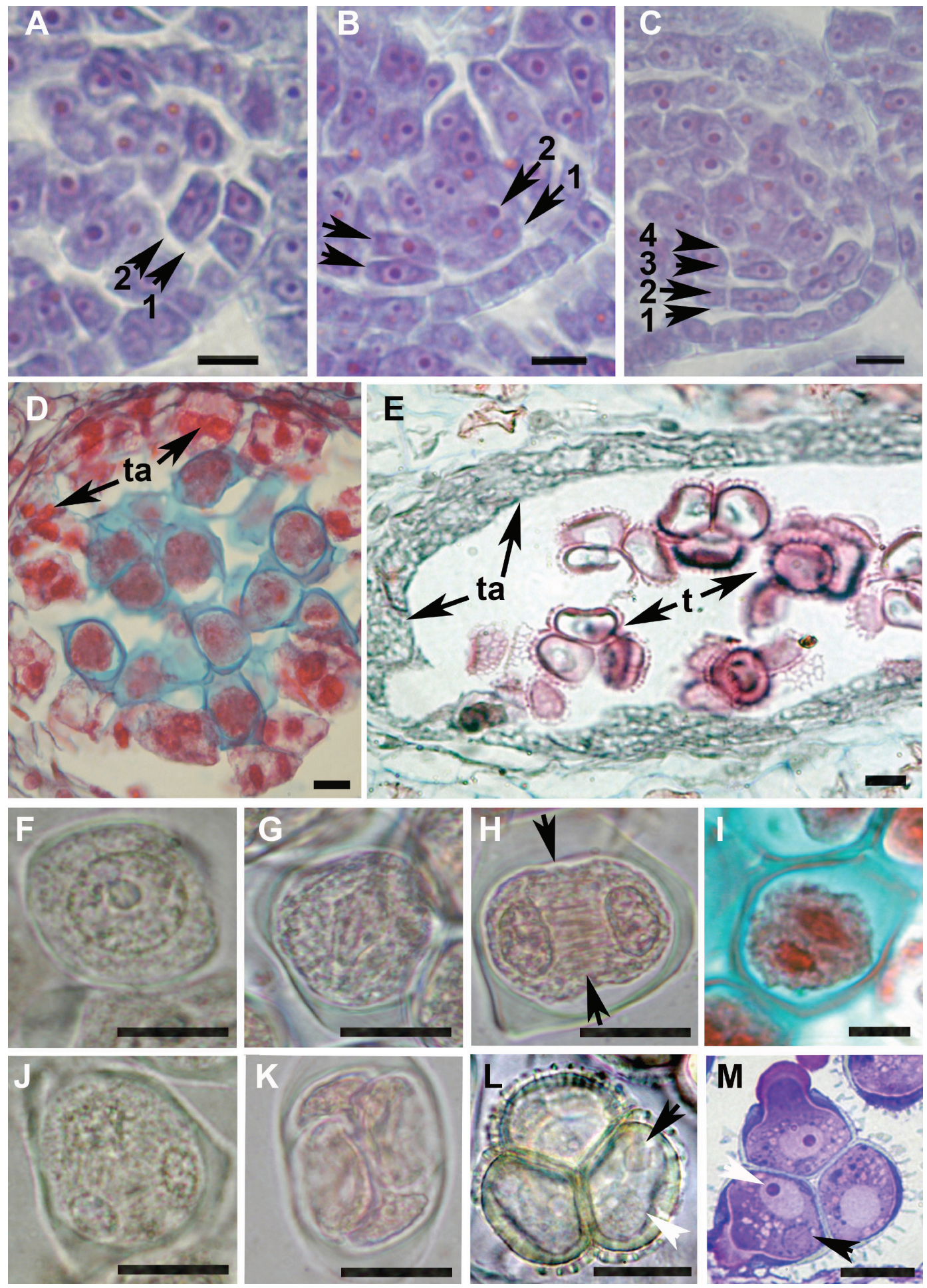
Ontogenia del gineceo y estructura de los óvulos en D. granadensis: Pétalos, estambres y carpelos se presentan en número indefinido y disposición helicoidal en los primordios florales (Fig. 3A). Los carpelos (tres a nueve) se forman por divisiones en los flancos del ápice floral y se aprecian como primordios más o menos redondeados; cada primordio se desarrolla inicialmente por crecimiento marginal y en la zona abaxial (Fig. 3A), pero pronto empieza a ser evidente el desarrollo de un 'labio adaxial' ('adaxial lip'; sensu Tucker, 1959; Fig. 3B, Fig. 3C) el cual conforma, junto con las zonas marginales y abaxial, un anillo continuo que crece dando lugar a la porción ascidiada del carpelo (Fig. 3D y Fig. 3E en sección transversal, Fig. 3G y Fig. $3 \mathrm{H}$ en sección longitudinal). La vascularización de los carpelos depende de los haces vasculares remanentes luego de la irrigación de la caliptra, los pétalos y los estambres. En la base de cada carpelo el único haz que llega desde el receptáculo se divide en tres trazas procambiales, dos ventrales y una dorsal (Fig. 3D, Fig. 3E).
El carpelo maduro presenta células taníferas en la epidermis externa (Fig. 3G y Fig. $3 \mathrm{H}$ ); el parénquima cortical presenta células taníferas y oleíferas. La placentación en forma de ' $U$ ' se da alrededor de la zona interna cercana al estigma. En la región estigmática la fusión de los márgenes del carpelo se da por interdigitación de las células epidérmicas. Las células epidérmicas externas del estigma son papiladas, mucho mayores que las epidérmicas presentes en el resto del carpelo y su naturaleza es glandular.

Cada carpelo presenta de 8-12 óvulos. Los óvulos conforman primero el integumento anular externo (Fig. 3F) y luego el integumento semianular interno, el cual está interrumpido por el lado cóncavo del funículo; el micrópilo parece estar conformado tan solo por el integumento interno cuando el saco embrionario esta maduro (Fig. 3K, Fig. 3L). En cuanto al desarrollo del megasporangio, una sola célula arquesporial inicial se diferencia en la nucela y se divide transversalmente para dar lugar a la célula parietal primaria y la célula madre

Fig. 3. A. Ápice de botón floral de D. granadensis con pétalos removidos visto en microscopía electrónica de barrido; B-L. Desarrollo y morfología de los carpelos en D. granadensis (Marquínez 003; Microscopía óptica, safranina-verde rápido); B. Sección longitudinal del ápice de un primordio floral; C. Detalle de los carpelos de mostrando el desarrollo de los labios abaxial y adaxial; D-E. Secciones transversales de carpelos con inicio de diferenciación de haces vasculares (flechas); G. Sección longitudinal de primordio floral; H. Detalle de G, nótese el desarrollo de la porción ascidiada del carpelo, el estigma aún no se ha formado; F,I,J. Desarrollo del óvulo en Drimys granadensis (Marquínez 003); F. Óvulo muy jóven, integumento interno y externo (flechas) en formación; I. Detalle de las capas de tejido parietal y la célula madre de la megáspora; J. Detalle de saco embrionario mostrando la ovocélula y dos sinérgidas en el polo micropilar; K. óvulo con saco embrionario mostrando las antípodas; L. Óvulo anátropo maduro; nótese la vascularización a partir del haz vascular ventral del carpelo. $\mathbf{a}=$ antípodas, $\mathbf{a b}=$ labio abaxial, $\mathbf{a d}=$ labio adaxial, $\mathbf{c}=$ carpelo, $\mathbf{c m m}=$ célula madre de la megáspora, $\mathbf{c t p}=$ capas de tejido parietal, $\mathbf{e}=$ estambre, $\mathbf{f}=$ funículo, $\mathbf{i e}=$ integumento externo, $\mathbf{i i}=$ integumento interno, $\mathbf{m}=$ micrópilo, $\mathbf{0}=$ óvulo, ov = ovocélula, $\mathbf{s}=$ sinérgidas, tc = tubo carpelar. Microscopía electrónica de barrido en A; Microscopía óptica (MO), safranina-fastgreen B-L. Escalas: $200 \mu \mathrm{m}$ en A,G; $100 \mu \mathrm{m}$ en $\mathbf{B} ; 50 \mu \mathrm{m}$ en $\mathbf{E}, \mathbf{K} ; 10 \mu \mathrm{m}$ en $\mathbf{C , D , F , L ~ y ~} 2 \mu \mathrm{m}$ en I,J.

Fig. 3. A. Flower bud apex of $D$. granadensis without petals seen in scanning electronic microscopy; B-L. Development and morphology of the carpels in D. granadensis (Marquínez 003; optical microscopy, safranine-fastgreen); B. Longitudinal section of the apex of a floral primordium; C. Detail of the carpels shwing the development of abaxial and adaxial lips; D-E. Carpels transversal sections with onset of differentiation of vascular bundles (arrows); G. Longitudinal section of floral primordia; H. Detail of $\mathbf{G}$, note the development of ascidiade portion of the carpel, stigma has not yet been formed; F,I-J. Ovule development in D. granadensis (Marquínez 003); F. Young ovule, inner and outer integument (arrows) in formation; I. Detail of parietal tissue layers and megaspore mother cell; J. Detail of embryo sac showing ovocell and two synergids at the micropylar pole; K. Ovule with embryo sac showing the antipodes; L. Mature anatropous ovule; note the vascularization from carpel ventral vascular bundle. $\mathbf{a}=$ antipodes, $\mathbf{a b}=$ abaxial lip, $\mathbf{a d}=$ adaxial lip, $\mathbf{c}=$ carpel, $\mathbf{c m m}=$ megaspore mother cell, $\mathbf{c t p}=$ parietal tissue layers, $\mathbf{e}=$ stamen, $\mathbf{f}=$ funiculus, $\mathbf{i e}=$ external integument, $\mathbf{i i}=$ inner integument, $\mathbf{m}=$ micropyle, $\mathbf{o}=$ ovule, $\mathbf{o v}=$ egg cell, $\mathbf{s}=$ synergids, tc $=$ carpelar tube. Scales: $200 \mu \mathrm{m}$ in $\mathbf{A}, \mathbf{G} ; 100 \mu \mathrm{m}$ in B; $50 \mu \mathrm{m}$ in $\mathbf{E}, \mathbf{K} ; 10 \mu \mathrm{m}$ in $\mathbf{C , D}, \mathbf{F}, \mathbf{L}$ and $2 \mu \mathrm{m}$ in $\mathbf{I}, \mathbf{J}$. 

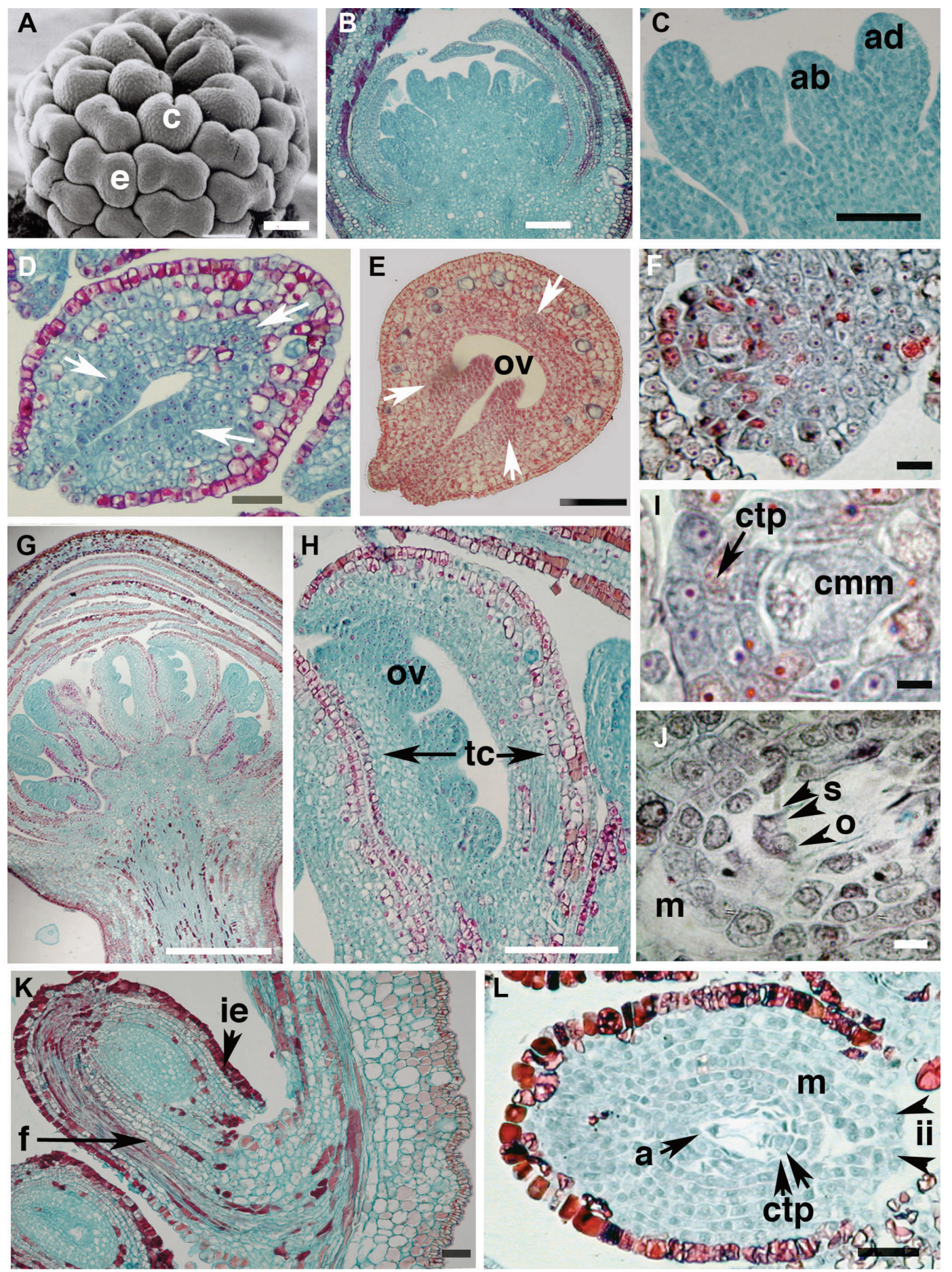
de la megáspora. La célula parietal se divide periclinal y anticlinalmente para dar lugar a dos o tres capas de tejido parietal de tal manera que el óvulo es de tipo crasinucelar (Fig. 3F, Fig. 3I). La división de la célula madre de la megáspora es lineal, generando tres megasporas degeneradas en dirección al micrópilo. El saco embrionario es de tipo Polygonum, ovocélula y dos sinérgidas en el extremo micropilar (Aparato ovocelular, flecha; Fig. 3J), una célula madre del endosperma diploide en posición central y tres antípodas en el extremo calazal (Fig. 3L). Los óvulos maduros anátropos carecen de hipostasa u obturador; se presentan células taníferas en la capa más interna del integumento interno alrededor del micrópilo y en la capa más externa del integumento externo (Fig. 3K, Fig. 3L).

\section{DISCUSIÓN}

Aunque la presencia y localización de células oleíferas en pétalos y estambres es utilizada por diversos autores, entre ellos Smith (1943), en las claves taxonómicas del género Drimys, su significado anatómico no había sido explorado con anterioridad, ni tampoco sus posibles implicaciones ecológicas. Los resultados de este trabajo en las especies del género Drimys, junto con los resultados de Marquínez (2009) en especies de los otros géneros de la familia, permiten señalar que el conectivo externamente no glandular de los estambres es una plesiomorfía de las Winteraceae; en tanto que la presencia de células oleíferas idioblásticas que alcanzan un gran tamaño y conforman protuberancias amarillas muy conspicuas y generalmente apicales en los estambres es una sinapomorfía del "clado nororiental" (D. angustifolia, D. brasiliensis, D. granadensis y $D$. roraimensis), de distribución tropical, (esta investigación; Marquínez, 2009; Marquínez et al., 2009b). En D. roraimensis, la cantidad y protrusión de células oleíferas en el conectivo pudo haber sido la razón por la cual Smith (1943) lo describió equívocamente como apiculado.
Marquínez, Sarmiento, y Lara (2009a) señalaron la importancia de los exudados estaminales en la atracción de una gran variabilidad de insectos (coleópteros y dípteros), coincidiendo, a nivel de grandes grupos, pero no a nivel genérico o específico, con los encontrados por Gottsberger, Gottsberger, y Ehrendorfer (1980) en Drimys brasiliensis en Brasil y por Thien (1980) en D. granadensis en Chiapas-México.

Weberling (2007) señala, y las filogenias y análisis biogeográficos reportados por Marquínez et al. (2009b) confirman, que los ancestros de Drimys, así como el clado suroccidental, son de zona templada a subantártica; proponiendo el levantamiento de los Andes como un evento asociado al origen y especiación del clado nororiental; en este contexto, señala Weberling (2007), extendieron su área en las cadenas montañosas que cruzan los trópicos. La frecuente necesidad de invadir nuevos hábitats puede haber prevenido la evolución de relaciones fuertes con polinizadores particulares. Cada nuevo sitio tiene una fauna diferente y característica e impredecible, a veces con más moscas, a veces con más escarabajos, más mariposas o trips (Gottsberger, 1988).

Por otra parte, en el clado suroccidental, la única especie cuya biología reproductiva ha sido analizada en detalle, D. confertifolia, es endémica del Archipielago de Juan Fernández y presenta polinización anemófila (Anderson, Bernardello, Stuessy, \& Crawford, 2001). Ante la sorprendente ausencia de información referente a la biología reproductiva y polinización en las otras dos especies de este último clado, $D$. winteri y D. andina, solo podemos sugerir como hipótesis que las condiciones altamente variables en zonas tropicales, asociadas a una amplia gama de polinizadores, estarían asociadas al surgimiento de estambres conspicuamente glandulares. Supondríamos, a manera de hipótesis, una menor variabilidad de polinizadores (o incluso especies anemófilas) en las especies circunscritas a la zona templada del Sur de Suramérica.

D. granadensis (esta investigación) y D. winteri (Bhandari y Venkataram, 1968; Tucker, 1959) coinciden en varios caracteres 
estudiados: formación de la pared de la antera de tipo básico, tapetum secretor que colapsa en la madurez, microsporogénesis de tipo intermedio con formación de placa celular transitoria y carpelo ascidiado debido a la presencia de un labio adaxial durante el desarrollo. En este último caracter, confirmamos la propuesta de que la diferencia fundamental entre carpelo ascidiado en el género Drimys y plicado en Tasmannia es la ausencia de un labio adaxial en su ontogenia (Tucker, 1959; Tucker \& Gifford 1966a; Tucker \& Gifford 1966b; Tucker \& Sampson, 1979).

\section{AGRADECIMIENTOS}

A Favio González por sus valiosos comentarios y orientaciones en la elaboración del escrito y la investigación; al Instituto para el Desarrollo de la Ciencias y la Tecnología "Francisco José de Caldas" (COLCIENCIAS) por el préstamo-beca mediante el Programa de apoyo a doctorados nacionales 2004 y a la Universidad Nacional de Colombia por la contrapartida.

\section{RESUMEN}

La familia Winteraceae ha sido tradicionalmente considerada como de diversificación temprana entre las angiospermas por varios caracteres, entre ellos: flores con muchas partes distribuidas en espiral y ovario apocarpico formado por carpelos de tipo plicado con estigma sésil. En el género Drimys, la presencia o ausencia de glándulas conspicuas sobre el conectivo de los estambres ha sido usado como un carácter taxonómico, y su presencia se considera como una sinapomorfía del clado formado por Drimys angustifolia, D. brasiliensis, D. granadensis and $D$. roraimensis (clado nororiental); sin embargo, la anatomía de estambres o carpelos ha sido solamente estudiada en detalle en $D$. winteri (clado suroccidental). En esta investigación, la presencia y estructura de las glándulas del conectivo fue estudiada en las siete especies del género Drimys a partir de ejemplares de herbario, además, se realizó un estudio detallado de la anatomía y desarrollo de estambres y carpelos de Drimys granadensis empleando microscopía óptica y microscopía de barrido; y se compararon con los resultados previos en Drimys winteri. Se encontraron similitudes en los siguientes caracteres: formación de la pared de la antera de tipo básico, tapetum secretor que colapsa en la madurez, microsporogénesis de tipo intermedio con formación de una placa celular transitoria en telofase I, carpelo ascidiado debido a la formación de un labio adaxial durante el desarrollo, estigma cerrado por interdigitación de células epidérmicas. Se determinó que las glándulas de gran tamaño sobre el conectivo de la antera madura se originaron por sobrecrecimiento de células oleíferas subepidérmicas, siendo una sinapomorfía del clado nororiental, que esta ausente tanto en el clado suroccidental de Drimys (D. andina, D. confertifolia y D. winteri), como en el resto de la familia. Se propone la hipótesis de que las condiciones altamente variables en las zonas tropicales donde se distribuye el clado nororiental de Drimys, con una amplia gama de polinizadores, estarían asociadas al surgimiento de estambres conspicuamente glandulares; en tanto que proponemos como predicción que las especies circunscritas a la zona templada del Sur de Suramérica (Clado suroccidental), sin glándulas conspicuas, deberían presentar una menor variedad de visitantes y/o polinizadores, o incluso ser especies anemófilas como Drimys confertifolia.

Palabras clave: microesporogenesis, carpelo ascidiado, células oleíferas idioblásticas, tapetum secretor.

\section{REFERENCIAS}

Anderson, G. J., Bernardello, G., Stuessy, T. F., \& Crawford, D. J. (2001). Breeding and pollination of selected plants endemic to Juan Fernandez Islands. American Journal of Botany, 88, 220-233.

Bailey, I. W. \& Nast, C. G. (1943). The comparative morphology of the Winteraceae. I. Pollen and stamens. Journal of Arnold Arboretum, 24, 340-346.

Bailey, I. W. \& Swamy, B. G. L. (1951). The conduplicate carpel of dicotyledons and its initials trends of specialization. American Journal of Botany, 38, 373-379.

Bhandari, N. N. (1963). Embryology of Pseudowintera colorata - A vesselless dicotyledon. Phytomorphology, 13, 303-316.

Bhandari, N. N. (1971). Embryology of the Magnoliales and comments on their relationships. Journal of Arnold Arboretum, 52, 1-39, 285-304.

Bhandari, N. N. \& Venkataram, R. (1968). Embryology of Drimys winteri. Journal of Arnold Arboretum, 49, 509-525.

Cairney, H. (1984). Some aspects of the floral anatomy, morphology and embryology of Belliolum sp. nov. (BSc honours project). Victoria University of Wellington, Wellington, Australia.

Canright, J. E. (1952). The comparative morphology and relationships of the Magnoliaceae. I. Trends of specialization in the stamens. American Journal of Botany, 39, 484-497.

Cronquist, A. (1981). An Integrated System of Classification of Flowering Plants. New York: Columbia University Press. 
Dahlgren, G. (1991). Steps toward a natural system of the dicotyledons: Embriological characters. Aliso, 13, 107-165.

Doyle, J. A. \& Endress, P. K. (2000). Morphological phylogenetic analysis of basal angiosperms: comparison and combination with molecular data. International Journal of Plant Science, 161, S121-S153.

Eames, A. J. (1961). Morphology of the Angiosperms. New York: McGraw-Hill.

Endress, P. K. \& Hufford, L. D. (1989). The diversity of stamen structure and dehiscence patterns among Magnoliidae. Botanical Journal of the Linnean Society, 100, 45-85.

Endress, P. K. \& Igersheim, A. (2000). Gynoecium structure and evolution in basal angiosperms. International Journal of Plant Science, 161(6 Suppl.): S211-S223.

Endress, P. K., Igersheim, A., Sampson, F. B., \& Schatz, G. E. (2000). Floral structure of Takhtajania perrieri and its systematic position in Winteraceae. Annals of the Missouri Botanical Garden, 87, 347-365.

Endress, P. K. \& Doyle, J. A. (2009). Reconstructing the ancestral angiosperm flower and its initial specializations. American Journal of Botany, 96, 22-66.

Endress, P. K. (2011). Angiosperm ovules: diversity, development, evolution. Annals of Botany, 107, 1465-1489.

Fiser, J. \& Walker, D. (1967). Notes on the pollen morphology of Drimys Forst., section Tasmannia (R. Br.) F. Muell. Pollen et Spores, 9, 229-239.

Furness, C. A., Rudall, P. J., \& Sampson, F. B. (2002). Evolution of microsporogenesis in angiosperms. International Journal of Plant Science, 163, 235-260.

González, F. \& Rudall, P. J. (2003). Structure and development of the ovule and seed in Aristolochiaceae, with particular reference to Saruma. Plant Systematics and Evolution, 241, 223-244.

Gottsberger, G., Gottsberger, I. S., \& Ehrendorfer, F. (1980). Reproductive biology in the primitive relict angiosperm Drimys brasiliensis (Winteraceae). Plant Systematics and Evolution, 135, 11-39.

Gottsberger, G. (1988). The reproductive biology of primitive angiosperms. Taxon, 37, 630-643.

Igersheim, A. \& Endress, P. K. (1997). Gynoecium diversity and systematics of the Magnoliales and winteroids. Botanical Journal of the Linnean Society, 124, 213-271.

Imaichi, R., Kato, M., \& Okada, H. (1995). Morphology of the outer integument in three primitive angiosperm families. Canadian Journal of Botany, 73, 1242-1249.

Johansen, D. J. (1940). Plant Microtechnique. New York: McGraw-Hill Book.
Marquínez, X. (2009). Filogenia y biogeografía del género Drimys (Winteraceae). Bogotá, Colombia. (Tesis de Doctorado). Universidad Nacional de Colombia, Bogotá, Colombia.

Marquínez, X., Sarmiento, R., \& Lara, K. (2009a). Fenología floral y visitantes florales en Drimys granadensis L.f. (Winteraceae). Acta biologica Colombiana, 14, 47-60.

Marquínez, X., Lohmann, L. G., Faria-Salatino, M. L., Salatino, A., \& González, F. (2009b). Generic relationships and dating of lineages in Winteraceae based on nuclear (ITS) and plastid (rpS16 and psbA-trnH) sequence data. Molecular Phylogenetics and Evolution, 53, 435-449.

Praglowski, J. (1979). Winteraceae Lindl. World pollen and spore flora, 8, 1-36.

Prakash, N., Lim A. L., \& Sampson, F. B. (1992). Anther and ovule development in Tasmannia (Winteraceae). Australian Journal of Botany, 40, 877-885.

Romero, G. (2003). Microscopía electrónica de transmisión (MET) área biomédica: Teoría y práctica. Bogotá, Colombia: Academia Colombiana de Ciencias Exactas, Físicas y Naturales.

Sampson, F. B. (1963). The floral morphology of Pseudowintera, the New Zealand member of the vesselless Winteraceae. Phytomorphology, 13, 403-423.

Sampson, F. B. (1970). Unusual features of cytokinesis in meiosis of pollen mother cells of Pseudowintera traverssi (Bouchan.) Dandy (Winteraceae). Beitraege zur Biologie der Pflanzen, 47, 71-77.

Sampson, F. B. (1974). A new pollen type of the Winteraceae. Grana, 14, 11-15.

Sampson, F. B. (1981). Synchronous versus asynchronous mitosis within permanent pollen tetrads of the Winteraceae. Grana, 20, 19-23.

Sampson, F. B. (1987). Stamen venation in the Winteraceae. Blumea, 32, 79-89.

Sampson, F. B. (2000a). The pollen of Takhtajania perrieri (Winteraceae). Annals of the Missouri Botanical Garden, 87, 380-388.

Sampson, F. B. (2000b). Pollen diversity in some modern magnoliids. International Journal of Plant Science, 161(6 suppl.), S193-S210.

Sampson, F. B. (2007). Variation and similarities in pollen features in some basal angiosperms, with some taxonomic implications. Plant Systematics and Evolution, 263, 59-75.

Schnarf, K. (1931). Vergleichende Embryologie der Angiospermen. Berlin: Borntraeger.

Smissen, R. (1993). Some aspects of the embryology of Exospermum stipitatum (Winteraceae). (BSc honours project). Victoria University of Wellington, Wellington, New Zealand. 
Smith, A. C. (1943). The American species of Drimys. Journal of the Arnold Arboretum, 24, 1-33.

Soltis, D. E., Soltis, P. S., Endress P. K., \& Chase, M. W. (2005). Phylogeny and evolution of angiosperms. Sunderland, Masachusetts: Sinauer Associates.

Swamy, B. G. L. (1952). Some aspects in the embryology of Zygogynum baillonii. The Proceedings of the National Academy of Sciences, India, Section B, 18, 399-406.

Takhtajan, A. L. (1980). Outline of the Classification of Flowering Plants (Magnoliophyta). Botanical Review, 46, 277-299.

Takhtajan, A. L. (1991). Evolutionary Trends in Flowering Plants. New York: Columbia University Press.

Thien, L. B. (1980). Patterrns of pollination in the primitive angiosperms. Biotropica, 12, 1-13.

Tobe, H. \& Sampson, B. (2000). Embryology of Takhtajania (Winteraceae) and a summary of embryological features for the family. Annals of the Missouri Botanical Garden, 87, 389-397.

Tucker, S. (1959). Ontogeny of the inflorescence and flower in Drimys winteri var. chilensis. University of California Publications in Botany, 30, 257-336.

Tucker, S. \& Gifford, E. M. (1966a). Organogenesis in the carpellate flower of Drimys lanceolata. American Journal of Botany, 53, 433-442.

Tucker, S. \& Gifford, E. M. (1966b). Carpel development in Drimys lanceolata. American Journal of Botany, 53, 671-678.

Tucker, S. \& Sampson, F. B. (1979). The gynoecium winteraceous plants. Science, 203, 920-921.

Van der Ham, R. \& van Heuven, B. J. (2002). Evolutionary trends in Winteraceae pollen. Grana, 41, 4-9.

Weberling, F. (2007). The problem of generalized flowers: morphological aspects. Taxon, 56, 707-716. 
